\title{
Prognostic value of alveolar volume in systolic heart failure: a prospective observational study
}

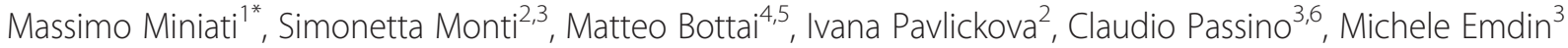 \\ and Roberta Poletti ${ }^{3}$
}

\begin{abstract}
Background: Ventilatory impairment is known to occur in patients with heart failure (HF). Alveolar volume $\left(V_{A}\right)$ is measured by the dilution of an inert gas during a single breath-hold maneuver. Such measurement is sensitive to ventilatory disturbances. We conducted a prospective, observational study to establish the prognostic value of $V_{\mathrm{A}}$ in systolic HF.
\end{abstract}

Methods: We studied 260 consecutive patients who were hospitalized for systolic HF. All patients were evaluated under stable clinical conditions, before hospital discharge. Lung function studies included spirometry and determination of the lung diffusing capacity for carbon monoxide $\left(\mathrm{DL}_{\mathrm{co}}\right)$ by the single-breath method. We also measured the cardiothoracic ratio on frontal chest radiographs, and the circulating levels of N-terminal pro-hormone of B-type natriuretic peptide (NT-proBNP). The hazard ratio (HR) of death was estimated with Cox regression, and the percentiles of survival time with Laplace regression. For survival analysis, $V_{\mathrm{A}}$ was categorized as $<80 \%$ ( $n=135)$, or $\geq 80 \%$ of the predicted value ( $n=125)$.

Results: Follow-up had a median duration of 2.7 years (interquartile range, 1.1 to 4.2 years). The crude mortality rate was $27 \%$ in the whole sample, $36 \%$ in patients with $V_{A}<80 \%$, and $16 \%$ in those with $V_{A} \geq 80 \%$. The HR of death was 2.3-fold higher in patients with $V_{A}<80 \%$ than in those with $V_{A} \geq 80 \%(p=0.002)$. After adjusting for age, New York Heart Association class III-IV, cardiothoracic ratio $>0.5$, NT-proBNP, persistent atrial fibrillation, DL comorbidity, use of beta-blockers and angiotensin converting enzyme inhibitors, the HR decreased to 1.9 but remained statistically significant $(p=0.039)$. Two percent of the patients with $V_{A}<80 \%$ died about 0.9 years earlier than those with $V_{A} \geq 80 \%(p=0.033)$. The difference in survival time at the 20th percentile was 0.8 years.

Conclusions: $V_{A}$ is a significant, independent predictor of reduced survival in patients with systolic HF.

Keywords: Systolic heart failure, Alveolar volume, Prognosis, Survival

\section{Background}

Heart failure (HF) is a common clinical disorder carrying significant morbidity and mortality $[1,2]$. Ventilatory impairment is known to occur in patients with HF, and is ascribed to factors such as heart enlargement, pulmonary stiffness due to chronic interstitial edema, and respiratory muscle dysfunction [3-7]. The coexistence of chronic airflow obstruction may add to ventilatory dysfunction, and is believed to have a negative prognostic impact in patients with chronic HF [8].

\footnotetext{
* Correspondence: massimo.miniati@unifi.it

${ }^{1}$ Dipartimento di Medicina Sperimentale e Clinica, Università di Firenze, Viale Morgagni 85, 50134 Firenze, Italy

Full list of author information is available at the end of the article
}

As of now, most of the studies on the prognostic impact of respiratory dysfunction in HF focused on simple spirometry [9-14], with only a few exploring the exchange of gases across the alveolar-capillary membrane $[15,16]$.

Alveolar volume $\left(\mathrm{V}_{\mathrm{A}}\right)$ is the volume of air in the lung available for gas exchange, and is currently measured by the dilution of an inert gas during a single breath-hold maneuver [17]. Due to the single-breath approach, such measurement is sensitive to ventilatory disturbances. In healthy subjects, $\mathrm{V}_{\mathrm{A}}$ equals total lung capacity (TLC) measured by multiple-breath helium dilution. In subjects with ventilatory impairment, $V_{A}$ is often much lower

\section{Biomed Central}


than TLC because of the insufficient mixing of gas in alveolar spaces [18].

We conducted a prospective, observational study aimed at establishing the prognostic value of $\mathrm{V}_{\mathrm{A}}$, as \% of the predicted value, in 260 consecutive patients with systolic HF. The outcome measure was all-cause mortality over a median follow-up time of about three years.

\section{Methods}

\section{Ethics statement}

The protocol was approved by the local ethics committee (Comitato Etico, Azienda Ospedaliero-Universitaria Pisana, Pisa, Italy). Before entering the study, the subjects provided an informed written consent.

\section{Sample}

The study sample comprised 260 consecutive patients with an established diagnosis of systolic HF. They were hospitalized at the CNR Institute of Clinical Physiology and "G. Monasterio" Foundation, Pisa, Italy, between January 1, 2000 and December 31, 2007. The diagnosis of $\mathrm{HF}$ was based on the Framingham criteria [19], and the finding of a left ventricular ejection fraction (LVEF) $<50 \%$ at transthoracic echocardiography. Patients were excluded if they had active cancer, recent (within 6 months) acute coronary syndromes, or pulmonary arterial hypertension.

\section{Study protocol}

All the patients were evaluated under stable clinical conditions, shortly before hospital discharge. Lung function studies included the measurement of slow (SVC) and forced vital capacity (FVC), forced expiratory volume in one second $\left(\mathrm{FEV}_{1}\right)$, and total lung capacity (TLC). At least three spirometric measurements were obtained and the highest values were chosen. Spirometry was performed by experienced technologists in conformity with the ATS/ERS standards [20]. The diagnosis of COPD was based on clinical and spirometric criteria (postbronchodilator ratio of $\mathrm{FEV}_{1} / \mathrm{SVC}$ below the 5th percentile of predicted value) [21]. The degree of airflow obstruction was categorized as mild, moderate, or severe if $\mathrm{FEV}_{1}$ was $>80 \%$, between 80 and $50 \%$, and $<50 \%$ of predicted, respectively. Ventilatory restriction was diagnosed if $\mathrm{FEV}_{1} / \mathrm{SVC}$ ratio was normal, and TLC below the 5th percentile of predicted [21]. The diffusing capacity of the lung for carbon monoxide $\left(\mathrm{DL}_{\mathrm{CO}}\right)$ was determined using the single-breath method in conformity with ATS/ERS recommendations [17]. $\mathrm{V}_{\mathrm{A}}$ was measured during the single-breath maneuver using helium as the inert gas [17].

Postero-anterior and lateral digital chest radiographs were obtained in all the subjects at the time of lung function testing, and were examined by two of the authors (MM, SM) for the presence of heart, pulmonary, and pleural abnormalities. On the postero-anterior view, we also measured the cardiothoracic ratio. This was regarded as abnormal if $>0.5$. We measured the circulating levels of hemoglobin, creatinine, and N-terminal pro-hormone of B-type natriuretic peptide (NT-proBNP). The latter was measured by an electrochemiluminescent sandwich immonoassay using Elecsys 2010 analyser (Roche Diagnostics, Germany) [22]. Medications prescribed at the time of hospital discharge were also recorded.

\section{Follow-up}

The 260 patients were followed up until death or March 31, 2009, whichever occurred first. All the subjects were seen periodically at the outpatient clinic of our institution. Whenever required, their family physicians were also contacted. The cause of death was established by reviewing medical records, autopsy findings, or death certificates.

\section{Statistical analysis}

Differences between groups were assessed by Fisher's exact test for the categorical variables, and by Mood's median test for the continuous variables. Continuous variables in the text and in the tables are reported as median and interquartile range (IQR). The association between $V_{A}$ and survival was evaluated with two methods: Cox proportional hazard regression to estimate hazard ratio (HR) for the risk of death, and Laplace regression to estimate the percentiles of survival time [23]. Survival percentiles may offer a comprehensive picture of the covariate effects on survival time while overcoming some of the known interpretational limitations of $\mathrm{HR}$ [24]. The main exposure of interest was $\mathrm{V}_{\mathrm{A}}$ which was categorized as $<80 \%$ or $\geq 80 \%$ of the predicted value. Based on univariate analysis, the following potential confounders were considered: tertiles of age $(\leq 61,62-71, \geq 72$ years), New York Heart Association (NYHA) class III-IV, cardiothoracic ratio $>0.5$, $\mathrm{DL}_{\mathrm{CO}}$ as \% predicted (split in two categories by the median value in the sample), tertiles of NT-proBNP ( $\leq 787,788-2058, \geq 2059 \mathrm{pg} / \mathrm{mL}$ ), persistent atrial fibrillation, COPD comorbidity, use of beta-blockers, and of angiotensin converting enzyme (ACE) inhibitors. The crude and adjusted percentiles, and the hazard ratios and associated 95\% confidence intervals (CI) are reported. The proportionality of the hazard in the Cox regression was tested based on the Schoenfeld residuals for each model separately. Two-tailed p-values $<0.05$ were considered statistically significant throughout. The statistical analysis was performed with Stata version 11 (StataCorp, College Station, TX). 


\section{Results \\ Sample}

The baseline characteristics of the study sample are given in Table 1. Based on clinical and spirometric data, COPD was diagnosed in 65 (25\%) of 260 cases; airflow obstruction was mild in 11 patients (17\%), moderate in $41(63 \%)$, and severe in $13(20 \%)$. In the whole sample, the median value of $\mathrm{V}_{\mathrm{A}}$ was $79 \%$ of predicted (IQR, 70 to $88 \%)$. There was a highly significant, inverse correlation of $\mathrm{V}_{\mathrm{A}}$ with NT-proBNP $(\mathrm{r}=-0.21 ; \mathrm{p}<0.001)$ and cardiothoracic ratio $(\mathrm{r}=-0.39 ; \mathrm{p}<0.001)$, and a weaker

Table 1 Baseline characteristics of 260 patients with systolic heart failure

\begin{tabular}{|c|c|c|}
\hline Characteristic & $\begin{array}{c}\text { Number } \\
\text { or Median }\end{array}$ & $\overline{\text { (Percent or IQR) }}$ \\
\hline Age, years & 68 & $(58-75)$ \\
\hline Male gender & 207 & $(80)$ \\
\hline $\mathrm{BMI}, \mathrm{kg} / \mathrm{m}^{2}$ & 26 & $(24-29)$ \\
\hline Current smoker & 50 & (19) \\
\hline NYHA class III-IV & 84 & $(32)$ \\
\hline LVEF, \% & 32 & $(25-40)$ \\
\hline Cardiothoracic ratio $>0.5$ & 162 & $(62)$ \\
\hline NT-ProBNP, pg/mL & 1302 & $(531-3028)$ \\
\hline Hemoglobin, g/dL & 13.7 & $(12.4-14.9)$ \\
\hline Creatinine, mmol/L & 101 & $(82-127)$ \\
\hline $\mathrm{FEV}_{1}, \%$ predicted & 87 & $(72-101)$ \\
\hline DLco, $\%$ predicted & 70 & $(61-81)$ \\
\hline COPD & 65 & $(25)$ \\
\hline Ventilatory restriction & 53 & $(20)$ \\
\hline Coronary artery disease & 115 & $(44)$ \\
\hline Hypertension & 141 & (54) \\
\hline Persistent atrial fibrillation & 51 & $(20)$ \\
\hline Prior stroke & 21 & (8) \\
\hline Diabetes & 82 & $(32)$ \\
\hline Dyslipidemia & 109 & $(42)$ \\
\hline Beta-blockers & 223 & $(86)$ \\
\hline ACE-inhibitors & 150 & $(58)$ \\
\hline Angiotensin receptor antagonists & 75 & $(29)$ \\
\hline Loop diuretics & 225 & $(87)$ \\
\hline Potassium sparing drugs & 175 & $(67)$ \\
\hline Warfarin & 42 & $(16)$ \\
\hline Implanted pace-maker & 35 & $(13)$ \\
\hline Implanted defibrillator & 13 & (5) \\
\hline
\end{tabular}

$\mathrm{IQR}=$ interquartile range. $\mathrm{BMI}=$ body mass index. $\mathrm{NYHA}=\mathrm{New}$ York Heart Association. LVEF = left ventricular ejection fraction. NT-proBNP $=\mathrm{N}$-terminal pro-hormone of $B$ type natriuretic peptide. $\mathrm{FEV}_{1}=$ forced expiratory volume in one second. $\mathrm{DL}_{\mathrm{CO}}=$ diffusing capacity of the lung for carbon monoxide. $\mathrm{COPD}=$ chronic obstructive pulmonary disease. $\mathrm{ACE}=$ angiotensing converting enzyme. borderline significant correlation with $\operatorname{LVEF}(\mathrm{r}=+0.11$; $\mathrm{p}=0.054)$.

Table 2 shows the characteristics of the study sample spit by $\mathrm{V}_{\mathrm{A}}$ category. As compared with patients having $\mathrm{V}_{\mathrm{A}} \geq 80 \%$, those with $\mathrm{V}_{\mathrm{A}}<80 \%$ featured the following statistically significant differences: (a) older age; (b) higher prevalence of NYHA class III-IV, abnormal cardiothoracic ratio, persistent atrial fibrillation, COPD comorbidity, and ventilatory restriction; (c) lower $\mathrm{FEV}_{1}$ and $\mathrm{DL}_{\mathrm{CO}}$; (d) higher levels of NT-proBNP. As regards medical treatment, significantly less patients with $\mathrm{V}_{\mathrm{A}}<80 \%$ were prescribed beta-blockers and ACE-inhibitors, and significantly more were on oral anticoagulants than those with $\mathrm{V}_{\mathrm{A}} \geq 80 \%$.

Radiologic signs of interstitial lung edema were detected in $16 \%$ of the patients with $\mathrm{V}_{\mathrm{A}}<80 \%$ and in $3 \%$ of those with $\mathrm{V}_{\mathrm{A}} \geq 80 \%(\mathrm{p}<0.001)$. Similarly, small pleural effusions prevailed significantly in the lower $\mathrm{V}_{\mathrm{A}}$ category than in the other $(24 \%$ vs $6 \%, \mathrm{p}<0.001)$, whereas no statistically significant difference was observed as regards the prevalence of radiologic signs of emphysema (11\% vs $7 \%, \mathrm{p}=0.293$ ). None of the sampled patients had evidence of overt lung fibrosis.

\section{Survival analysis}

Follow-up was completed in all the patients, and had a median duration of 2.7 years (IQR, 1.1 to 4.2 years). The crude mortality rate was $27 \%(69 / 260)$ in the whole sample, $36 \%(49 / 135)$ in patients with $\mathrm{V}_{\mathrm{A}}<80 \%$, and $16 \%$ $(20 / 125)$ in those with $V_{A} \geq 80 \%$. The causes of death were: heart failure $(n=44)$, cancer $(n=9)$, respiratory failure $(n=5)$, sudden death $(n=4)$, liver failure $(n=2)$, sepsis $(n=2)$, multiple trauma $(n=2)$, and renal failure $(\mathrm{n}=1)$.

Figure 1 shows the estimated cumulative incidence of death which was significantly higher in patients with $\mathrm{V}_{\mathrm{A}}<80 \%$ than in the others $(\mathrm{p}=0.032)$. The mortality curves are adjusted for age, NYHA class III-IV, cardiothoracic ratio $>0.5$, NT-proBNP, persistent atrial fibrillation, $\mathrm{DL}_{\mathrm{CO}}$ as \% predicted, and COPD comorbidity.

Table 3 describes the regression estimates of the HR of death for the two categories of $\mathrm{V}_{\mathrm{A}}$. The unadjusted $\mathrm{HR}$ of death in patients with $\mathrm{V}_{\mathrm{A}}<80 \%$ was 2.3 -fold higher than in those with $\mathrm{V}_{\mathrm{A}} \geq 80 \%(\mathrm{p}=0.002)$. After adjusting for potential confounders, the HR of death decreased to 1.9 but remained statistically significant $(p=0.039)$.

Laplace regression estimates of the percentiles of survival by $\mathrm{V}_{\mathrm{A}}$ category are displayed in Figure 2 . They are adjusted for age, NYHA class III-IV, cardiothoracic ratio $>0.5$, NT-proBNP, persistent atrial fibrillation, $\mathrm{DL}_{\mathrm{CO}}$ as \% predicted, and COPD comorbidity. Two percent of the patients with $\mathrm{V}_{\mathrm{A}}<80 \%$ died about 0.9 years earlier than those with $\mathrm{V}_{\mathrm{A}} \geq 80 \%(\mathrm{p}=0.033)$. The difference at the 20th percentile was 0.8 years. 
Table 2 Study sample split by alveolar volume

\begin{tabular}{|c|c|c|c|c|c|}
\hline \multirow{3}{*}{$\frac{\text { Characteristic }}{\text { Age, years }}$} & \multicolumn{4}{|c|}{ Alveolar volume (\% predicted) } & \multirow{3}{*}{$\begin{array}{r}\text { P-value } \\
<0.001\end{array}$} \\
\hline & \multicolumn{2}{|c|}{$<80(n=135)$} & \multicolumn{2}{|c|}{$\geq 80(n=125)$} & \\
\hline & 71 & $(66-77)$ & 64 & $(55-71)$ & \\
\hline Male gender & 109 & (81) & 98 & (78) & 0.648 \\
\hline $\mathrm{BMl}, \mathrm{kg} / \mathrm{m}^{2}$ & 26 & $(24-29)$ & 26 & $(23-30)$ & 1.000 \\
\hline Current smoker & 21 & (16) & 29 & (23) & 0.157 \\
\hline NYHA class III-IV & 57 & (42) & 27 & (22) & $<0.001$ \\
\hline LVEF, \% & 30 & $(25-38)$ & 33 & $(25-40)$ & 0.710 \\
\hline Cardiothoracic ratio $>0.5$ & 93 & (69) & 69 & (55) & 0.029 \\
\hline NT-ProBNP, pg/mL & 1607 & $(811-3878)$ & 982 & $(297-2141)$ & 0.003 \\
\hline Hemoglobin, g/dL & 13.6 & $(12.5-14.7)$ & 13.7 & $(12.4-15.0)$ & 0.552 \\
\hline Creatinine, $\mathrm{mmol} / \mathrm{L}$ & 105 & $(82-137)$ & 97 & $(82-114)$ & 0.139 \\
\hline $\mathrm{FEV}_{1}, \%$ predicted & 78 & $(65-87)$ & 99 & $(90-109)$ & $<0.001$ \\
\hline $\mathrm{DL}_{\mathrm{CO}}, \%$ predicted & 66 & $(53-75)$ & 76 & $(68-92)$ & $<0.001$ \\
\hline COPD & 42 & (31) & 23 & (18) & 0.022 \\
\hline Ventilatory restriction & 53 & (39) & 0 & (0) & $<0.001$ \\
\hline Coronary artery disease & 66 & (49) & 49 & (39) & 0.134 \\
\hline Hypertension & 75 & (56) & 66 & (53) & 0.709 \\
\hline Persistent atrial fibrillation & 34 & (25) & 17 & (14) & 0.020 \\
\hline Prior stroke & 10 & (7) & 11 & (9) & 0.821 \\
\hline Diabetes & 44 & (33) & 38 & (30) & 0.790 \\
\hline Dyslipidemia & 52 & (39) & 57 & (44) & 0.260 \\
\hline Beta-blockers & 107 & (79) & 116 & (93) & 0.002 \\
\hline ACE-inhibitors & 69 & (51) & 81 & (65) & 0.033 \\
\hline Angiotensin receptor antagonists & 40 & (30) & 35 & (28) & 0.786 \\
\hline Loop diuretics & 117 & (87) & 108 & (86) & 1.000 \\
\hline Potassium sparing drugs & 84 & (62) & 91 & (73) & 0.085 \\
\hline Warfarin & 28 & (21) & 14 & (11) & 0.043 \\
\hline Implanted pace-maker & 20 & (15) & 15 & (12) & 0.589 \\
\hline Implanted defibrillator & 5 & (4) & 8 & $(6)$ & 0.398 \\
\hline
\end{tabular}

Data are numbers (\%), or medians (interquartile range). For abbreviations see Table 1.

So, the frailest were the most affected individuals by reduced $\mathrm{V}_{\mathrm{A}}$.

\section{Discussion}

The present study was designed to establish whether $\mathrm{V}_{\mathrm{A}}$, as percent of the predicted value, is a prognostic indicator in systolic HF. Our results can be summarized thus: (a) the cumulative incidence of death is significantly higher in patients with $\mathrm{V}_{\mathrm{A}}<80 \%$ predicted than in those with $V_{A} \geq 80 \%$; (b) the estimated HR of death is about two-fold greater among the patients in the lower $V_{A}$ category, and remains significantly higher after adjusting for relevant confounding variables; (c) as indicated by Laplace regression, reduced $\mathrm{V}_{\mathrm{A}}$ is strongly associated with early deaths.
We found a significant, inverse correlation between $\mathrm{V}_{\mathrm{A}}$ and cardiothoracic ratio. This suggests that heart enlargement is a major determinant of reduced $V_{A}$ in chronic HF. Generalized stiffness of the lung parenchyma may also contribute to diminish $\mathrm{V}_{\mathrm{A}}$. Such reduced lung distensibility is due to chronic interstitial edema, and pulmonary vascular remodeling that are known to occur in long-standing HF [25].

We also observed that $\mathrm{V}_{\mathrm{A}}$ is significantly correlated with the circulating levels of NT-proBNP, an established prognostic biomarker of HF [2]. After adjusting for NT-proBNP, the HR of death associated with reduced $\mathrm{V}_{\mathrm{A}}$ remains statistically significant so indicating that $\mathrm{V}_{\mathrm{A}}$ is an independent predictor of survival.

A number of studies investigated on simple spirometry as a potential indicator of future cardiovascular events. 


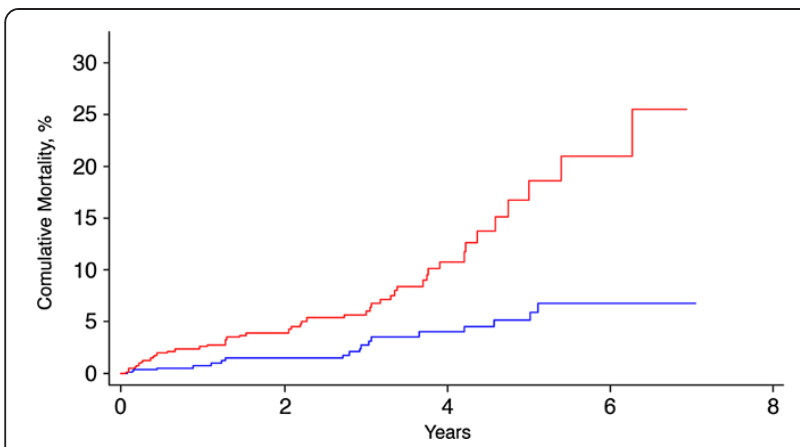

Figure 1 Estimated cumulative mortality in the study sample split by alveolar volume $\left(\mathrm{V}_{\mathrm{A}}\right)$ as \% predicted: $\mathrm{V}_{\mathrm{A}}<\mathbf{8 0 \%}$ (red step curve); $\mathbf{V}_{\mathbf{A}} \mathbf{2 8 0} \%$ (blue step curve). Estimates are adjusted for age, NYHA class III-IV, cardiothoracic ratio $>0.5$, NT-proBNP, persistent atrial fibrillation, $\mathrm{DL}_{\mathrm{CO}}$ as $\%$ predicted, and COPD comorbidity. P-value by log-rank test $=0.032$.

In the setting of the Framingham Study, Kannel et al. observed that FVC is a significant, independent predictor of cardiovascular morbidity and mortality in allegedly healthy subjects [9]. Later, Kannel et al. reported that FVC is a predictor of subsequent cardiac failure in individuals with coronary artery disease and left ventricular hypertrophy [10].

In recent years, there has been increasing interest in evaluating the prognostic impact of COPD comorbidity in patients with chronic HF. Mascarenhas et al. [11] conducted a retrospective study in 186 patients with systolic HF, and found no significant association between having COPD and all-cause mortality (HR 1.40, 95\% CI 0.88 to 2.44$)$. Only severe airflow obstruction $\left(\mathrm{FEV}_{1}<50 \%\right.$ of predicted value) appeared to be a predictor of reduced survival (HR 2.10, 95\% CI 1.05 to 4.22) [11]. In 527 patients with a clinical diagnosis of HF, Iversen et al. reported that $\mathrm{FEV}_{1}$ has independent prognostic value (HR 0.86 per $10 \%$ change with respect to the predicted value, $\mathrm{p}<0.001$ ) [12]. By contrast, Macchia et al. estimated an adjusted HR of death of 0.77 (95\% CI, 0.37 to 1.58) in patients with systolic HF and concomitant chronic airway obstruction, suggesting that COPD has no significant bearing on survival [13]. The three studies differ

Table 3 Estimated hazard ratios of death by alveolar volume category

\begin{tabular}{cccc}
\hline & \multicolumn{2}{c}{$\mathbf{V}_{\mathbf{A}}<\mathbf{8 0} \%$ versus $\mathbf{V}_{\mathbf{A}} \geq \mathbf{8 0} \%$} & \\
\cline { 2 - 3 } Model & Hazard ratio & $\mathbf{9 5 \%} \mathrm{Cl}$ & P-value \\
\hline 1 & 2.31 & $(1.37-3.90)$ & 0.002 \\
2 & 1.90 & $(1.03-3.50)$ & 0.039
\end{tabular}

$\mathrm{V}_{\mathrm{A}}=$ alveolar volume (as $\%$ predicted). $\mathrm{Cl}=$ confidence interval.

Model 1: unadjusted.

Model 2: adjusted for age, NYHA class III-IV, NT-proBNP, cardiothoracic ratio $>0.5$, persistent atrial fibrillation, $\mathrm{DL}_{\mathrm{CO}}$ as $\%$ predicted, COPD comorbidity, use of beta-blockers and of ACE-inhibitors.

For abbreviations, see Table 1.

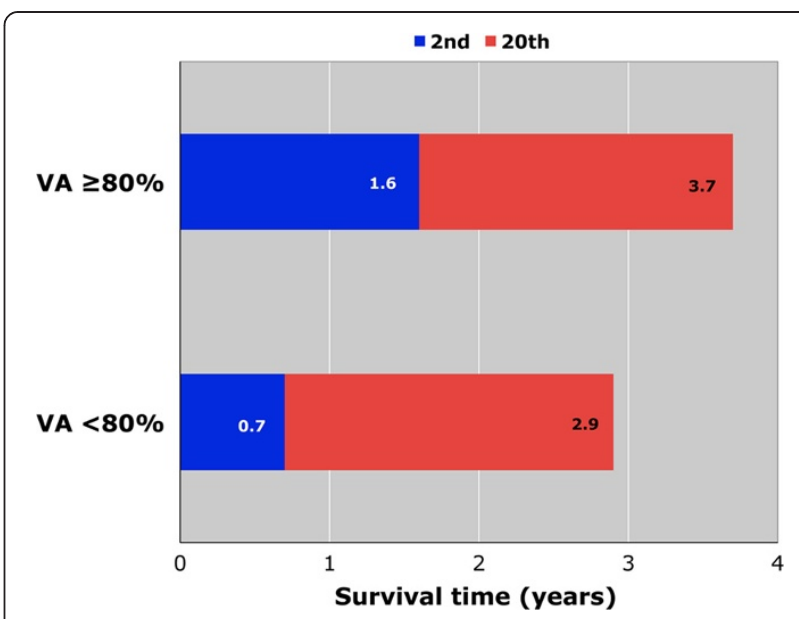

Figure 2 Laplace regression estimates of the 2nd and 20th percentile of survival time in the sample split by alveolar volume $\left(\mathrm{V}_{\mathrm{A}}\right)$ as $\%$ predicted ( $<\mathbf{8 0} \%$ vs $\mathbf{2 8 0} \%$ ). Estimates are adjusted for age, NYHA class III-IV, cardiothoracic ratio $>0.5$, NT-proBNP, persistent atrial fibrillation, $\mathrm{DL}_{\mathrm{CO}}$ as $\%$ predicted, and COPD comorbidity.

substantially for proportion of severe airflow obstruction, NYHA class III-IV, and duration of follow-up, and this may explain the inconsistent results obtained as regards the prognostic impact of COPD in HF.

Recently, Miniati et al. reported that a reduction of $\mathrm{FEV}_{1}$ - be it due to airflow obstruction or ventilatory restriction - is a significant, independent predictor of reduced survival in 439 patients with systolic HF [14]. In that study, the adjusted HR of death was 1.8-fold higher in patients with $\mathrm{FEV}_{1}<80 \%$ predicted as compared with those having $\mathrm{FEV}_{1} \geq 80 \%$ [14].

As of now, limited data is available on the prognostic relevance of lung function tests other than spirometry. It is well established that chronic HF brings about extensive remodeling of the pulmonary intra-alveolar vessels and interstitium [26], which may hamper the exchange of gases across the alveolar-capillary barrier [15]. In 106 patients with systolic HF, Guazzi and coworkers reported that alveolar-capillary membrane conductance of less than $24.7 \mathrm{~mL} / \mathrm{min} / \mathrm{mmHg}$ is significantly and independently associated with a worse outcome [16]. Partitioning of lung diffusing capacity into its membrane and capillary blood volume components requires the determination of $\mathrm{DL}_{\mathrm{CO}}$ at two different concentrations of oxygen in the inspired test bolus $[15,16]$. This technique is seldom used in routine clinical practice.

$\mathrm{V}_{\mathrm{A}}$ represents an estimate of the lung gas volume into which $\mathrm{CO}$ is distributed and, therefore, is critical in the measurement of $\mathrm{DL}_{\mathrm{CO}}$ with the single-breath approach [17]. In the presence of uneven distribution of ventilation, due to altered lung distensibility or airflow obstruction, $V_{\mathrm{A}}$ primarily reflects the volume of the airspaces 
into which the tracer gas rapidly equilibrates during the breath-hold time [17]. The estimated volume can, therefore, be regarded as reflecting the size of the well-ventilated lung regions. As shown in Table 2, spirometrically determined ventilatory restriction, was present in only 53 (39\%) of 135 patients with $\mathrm{V}_{\mathrm{A}}<80 \%$ predicted. So, we believe that measuring $\mathrm{V}_{\mathrm{A}}$ may add valuable information as regards lung function assessment in patients with systolic HF.

Undoubtedly, factors other than $\mathrm{V}_{\mathrm{A}}$ affect the lung diffusing capacity, including the physical properties of the alveolar membrane, the density of alveolar capillaries, and the hemoglobin concentration [17]. Thus, in multivariate analysis, we incorporated $\mathrm{DL}_{\mathrm{CO}}$ among the potential confounding variables. After adjustment, the HR of death associated with the lower $\mathrm{V}_{\mathrm{A}}$ category remained statistically significant.

\section{Study limitations}

First, we only studied patients with systolic HF, so our findings may not apply to patients with isolated diastolic heart dysfunction. Second, our data originated from a single referral center, and included a relatively small number of cases. Broader multicenter prospective studies are needed to firmly establish the prognostic value of $\mathrm{V}_{\mathrm{A}}$ in HF. Third, we obtained a single determination of $V_{A}$. So, it would of interest to evaluate the effect of cardiovascular and pulmonary medications on $\mathrm{V}_{\mathrm{A}}$ size over time, and to test whether improvement in $\mathrm{V}_{\mathrm{A}}$ is associated with a better oucome in patients with chronic HF.

\section{Conclusions}

The present study indicates that $V_{A}$, as percent of the predicted value, is a significant, independent predictor of reduced survival in patients with systolic HF.

\section{Competing interests}

The authors declare that they have no competing interests.

\section{Authors' contribution}

Study design (MM). Data collection (CP, ME, RP, IP). Data analysis (MM, SM, $\mathrm{MB})$. Drafting the manuscript (MM). Approval of the final version of the manuscript (all authors).

\section{Acknowledgments}

The authors wish to thank Concetta Prontera for the assay of NT-proBNP, Luca Serasini and Mirko Passera for preparing the artwork. Permission was obtained from those who are acknowledged.

\section{Funding}

No external funding was received for this study.

\section{Author details}

'Dipartimento di Medicina Sperimentale e Clinica, Università di Firenze, Viale Morgagni 85, 50134 Firenze, Italy. ${ }^{2}$ Istituto di Fisiologia Clinica del CNR, Pisa, Italy. ${ }^{3}$ Fondazione CNR-Regione Toscana "G. Monasterio", Pisa, Italy. ${ }^{4}$ Unit of Biostatistics, Karolinska Institutet, Stockholm, Sweden. ${ }^{5}$ Division of Biostatistics, Arnold School of Public Health, University of South Carolina, Columbia, SC, USA. ${ }^{6}$ Scuola Superiore di Studi Universitari e Perfezionamento "S. Anna", Pisa, Italy.
Received: 26 January 2013 Accepted: 4 November 2013

Published: 22 November 2013

\section{References}

1. Goldberg RJ, Ciampa J, Lessard D, Meyer TE, Spencer FA: Long-term survival after heart failure. A contemporary population-based perspective. Arch Intern Med 2007, 167:490-496.

2. Dickstein K, Cohen-Solal A, Filippatos G, McMurray JJV, Ponikovski P, PooleWilson PA, Strömberg A, van Veldhuisen DJ, Atar D, Hoes AW, Keren A, Mebazaa A, Nieminen A, Priori SG, Swedberg K: ESC guidelines for the diagnosis and treatment of acute and chronic heart failure 2008: the Task Force for the diagnosis and treatment of acute and chronic heart failure of the European Society of Cardiology. Developed in collaboration with the Heart Failure Association of the ESC (HFA) and endorsed by the European Society of Intensive Care Medicine (ESICM). Eur Heart J 2008, 29:2388-2442.

3. Hosenpud JD, Stibolt TA, Atwal K, Shelley D: Abnormal pulmonary function specifically related to congestive heart failure: comparison of patients before and after cardiac transplantation. Am J Med 1990, 88:493-496.

4. Naum CC, Sciurba FC, Rogers RM: Pulmonary function abnormalities in chronic severe cardiomyopathy preceding heart transplantation. Am Rev Respir Dis 1992, 145:1334-1338.

5. Wasseman K, Zhang YY, Gitt A, Belardinelli R, Koike A, Lubarsky L, Agostoni PG: Lung function and exercise gas exchange in chronic heart failure. Circulation 1997, 96:2221-2227.

6. Meyer FJ, Borst MM, Zugck C, Kirschke A, Shellenberg D, Kubler W, Haass M: Respiratory muscle dysfunction in congestive heart failure: clinical correlation and prognostic significance. Circulation 2001, 103:2153-2158.

7. Olson TP, Kenneth CB, Johnson BD: Pulmonary function changes associated with cardiomegaly in chronic heart failure. J Card Fail 2007, 13:100-107.

8. Hawkins NM, Petrie MC, Jhund PS, Chalmers GW, Dunn FG, McMurray Jj: Heart failure and chronic obstructive pulmonary disease: diagnostic pitfalls and epidemiology. Eur J Heart Fail 2009, 11:130-139.

9. Kannel WB, Hubert H, Lew FA: Vital capacity as a predictor of cardiovascular disease: the Framingham Study. Am Heart J 1983, 105:311-315.

10. Kannel WB, D'Agostino RB, Silbershatz H: Use of vital capacity for cardiac failure risk estimation in persons with coronary disease and left ventricular hypertrophy. Am J Cardiol 1996, 77:1155-1158.

11. Mascarenhas J, Lourenço P, Lopes R, Azevedo A, Bettencourt P: Chronic obstructive pulmonary disease in heart failure. Prevalence, therapeutic and prognostic implications. Am Heart J 2008, 155:521-525.

12. Iversen KK, Kjaergaard J, Akkan D, Kober L, Torp-Pedersen C, Hassager C, Vestbo J, Kjoller E, ECHOS-Lung Function Study Group: The prognostic importance of lung function in patients admitted with heart failure. Eur $\lrcorner$ Heart Fail 2010, 12:685-691.

13. Macchia A, Rodriguez Moncalvo JJ, Kleinert M, Comignani PD, Gimenoe G, Arakaki D, Laffaye N, Fuselli JJ, Massolin HP, Gambarte J, Romero M, Tognoni G: Unrecognized ventricular dysfunction in COPD. Eur Respir J 2012, 39:51-58.

14. Miniati M, Monti S, Bottai M, Passino C, Emdin M, Poletti R: Forced expiratory volume in one second: prognostic value in systolic heart failure. Int J Cardio/ 2013. http://dx.doi.org/10.1016/j.ijcard.2013.01.170.

15. Puri S, Baker BL, Oakley CM, Hughes JMB, Cleland JGF: Increased alveolar/ capillary membrane resistance in patients with chronic heart failure. Br Heart J 1994, 72:140-144.

16. Guazzi M, Pontone G, Brambilla R, Agostoni P, Reina G: Alveolar-capillary membrane conductance: a novel prognostic indicator in chronic heart failure. Eur Heart J 2002, 23:467-476.

17. MacIntyre N, Crapo RO, Viegi G, Johnson DC, van der Grinten CPM, Brusasco V, Burgos F, Casaburi R, Coates A, Enright P, Gustafsson P, Hankinson J, Jensen R, McKay R, Miller MR, Navajas D, Pedersen OF, Pellegrino R, Wanger J: Standardisation of the single-breath determination of carbon monoxide uptake in the lung. Eur Respir $J$ 2005, 26:720-735.

18. Roberts CM, MacRae KD, Seed WA: Multibreath and single breath helium dilution lung volumes as a test of airway obstruction. Eur Respir J 1990, 3:515-520.

19. McKee PA, Castelli WP, McNamara PM, Kannel WB: The natural history of congestive heart failure: the Framingham study. N Engl J Med 1971, 285:1441-1446. 
20. Miller MR, Hankinson J, Brusasco V, Burgos F, Casaburi R, Coates A, Crapo R, Enright P, van der Grinten CP, Gustafsson P, Jensen R, Johnson DC, Maclntyre N, McKay R, Navajas D, Pedersen OF, Pellegrino R, Viegi G, Wanger J: Standardisation of spirometry. Eur Respir J 2005, 26:319-338.

21. Pellegrino R, Viegi G, Brusasco V, Crapo RO, Burgos F, Casaburi R, Coates A, van der Grinten CP, Gustafsson P, Hankinson J, Jensen R, Johnson DC, Maclntyre N, McKay R, Miller MR, Navajas D, Pedersen OF, Wanger J: Interpretative strategies for lung function tests. Eur Respir J 2005, 26:948-968.

22. Prontera C, Emdin M, Zucchelli GC, Ripoli A, Passino C, Clerico A: Natriuretic peptides (NPs): automated electrochemiluminescent immunoassay for $\mathrm{N}$-terminal pro-BNP compared with IRMA for ANP and BNP in heart failure patients and healthy individuals. Clin Chem 2003, 49:1552-1554.

23. Bottai $M$, Zhang J: Laplace regression with censored data. Biometrical J 2010, 52:487-503.

24. Hernán MA: The hazard of hazard ratios. Epidemiology 2010, 21:13-15.

25. Wagenvoort CA, Mooi WJ: Biopsy Pathology of the Pulmonary Vasculature. London: Chapman \& Hall; 1989:170-198.

26. Bachofen $H$, Bachofen $M$, Weibel ER: Ultrastructural aspects of pulmonary edema. J Thorac Imag 1988, 3:1-7.

doi:10.1186/1471-2466-13-69

Cite this article as: Miniati et al:: Prognostic value of alveolar volume in systolic heart failure: a prospective observational study. BMC Pulmonary Medicine 2013 13:69.

\section{Submit your next manuscript to BioMed Central and take full advantage of:}

- Convenient online submission

- Thorough peer review

- No space constraints or color figure charges

- Immediate publication on acceptance

- Inclusion in PubMed, CAS, Scopus and Google Scholar

- Research which is freely available for redistribution 